\title{
Hume: sus aportes al análisis del lenguaje moral
}

\author{
Hume: His Contributions \\ to Moral Language Analysis
}

\author{
NICOLÁS ZAVADIVKER \\ Conicet/ Universidad Nacional de Tucumán \\ Recibido: 07/VI/2014 Aceptado definitivamente: 19/VI/2014
}

\section{RESUMEN}

El objetivo de este trabajo es reconstruir los diferentes aportes realizados por David Hume al análisis del lenguaje moral y de la argumentación práctica, es decir, a las cuestiones que hoy se agrupan bajo de el nombre de Metaética. Muchas de sus puntualizaciones y argumentos son conocidos y tuvieron una notable influencia en la metaética contemporánea, pero otros pasajes de su obra no tuvieron tal atención, y es mi interés resaltarlos y destacar su importancia. En este artículo me ocuparé de unos y de otros.

\section{PALABRAS CLAVE \\ HUME-METAÉTICA-SUBJETIVISMO AXIOLÓGICO-GUILLOTINA DE HUME- LENGUAJE MORAL}

\begin{abstract}
The objective of this study is to reconstruct the different contributions made by David Hume to the analysis of moral language and practical argumentation, issues which today are grouped as Metaethics. Many of his points and arguments are known and had a remarkable influence on the contemporary metaethics, but other passages of his work had no such attention, and is my interest, highlight them and its importance. In this article I will deal with ones and others.
\end{abstract}




\section{KEY WORDS \\ HUME METAETHICS-AXIOLOGICAL SUBJETIVISM-HUME'S GUILLOTINE-MO- RAL LENGUAGE}

COMO ES SABIDO, la obra de David Hume en materia ética ha dado lugar a una variedad de interpretaciones diferentes. La polémica se ha extendido incluso al terreno metaético: hay quienes afirman que Hume defendió una posición subjetivista, quienes lo consideran el «abuelo» del emotivismo y quienes le atribuyen una posición cognitivista que tiene por base la naturaleza humana.

Independientemente de esta disputa, e incluso de la propia posición adoptada por Hume en este terreno, quisiera rescatar en este trabajo algunos aportes realizados por el filósofo escocés a la metáetica general, es decir, aquellas ideas que nos legó que poseen un gran interés a los fines de dilucidar el lenguaje moral y la argumentación práctica. Es claro que Hume no es solamente un filósofo destacado debido a la importancia de sus doctrinas, sino también por haber elaborado una serie de argumentos refinados y comentarios críticos, y cuya validez no depende de los aciertos de sus posiciones generales.

Muchas puntualizaciones sobre el lenguaje moral son conocidas y tuvieron una notable influencia en la metaética contemporánea. Otros pasajes de la obra humeana, en cambio, no tuvieron tal atención, y parte del objetivo de este trabajo consistirá en resaltarlos y destacar su importancia.

Comenzaré con una breve presentación de la problemática metaética en general. Esta disciplina, iniciada por G.E. Moore a principios del siglo XX, tiene como centro de interés el análisis del lenguaje moral. Así, la metaética intenta responder interrogantes tales como: ¿qué decimos cuando decimos que algo es 'bueno'?, o bien, ¿qué características son propias del lenguaje moral? Se trata, pues, de un discurso elucidatorio que se ocupa a su vez de otro discurso, el moral. Actualmente incluye no sólo asuntos relativos al significado y uso de los términos morales, sino también cuestiones vinculadas a la argumentación moral y a la posible lógica de los enunciados morales.

\section{LA GUillotina De Hume}

Sin duda, el principal atractivo de Hume para los metaéticos contemporáneos fue su denuncia de la imposibilidad de deducir enunciados normativos a partir de enunciados descriptivos, argumento conocido como la Guillotina o Ley de Hume. Representantes de diversas corrientes metaéticas de la filosofía analítica citaron el pasaje humeano en apoyo de sus propias visiones de la ética. Así lo hicieron, por ejemplo, el intuicionista Harold Prichard, el emotivista Alfred Ayer y el prescriptivista Richard Hare. Por su parte, Karl Popper sugirió que la consideración lógica de Hume es la puntualización más 
importante realizada en materia ética, ${ }^{1}$ valoración similar a la realizada por P. H. Nowell-Smith. ${ }^{2}$

Dada la brevedad y contundencia con que el pensador escocés expuso su argumento, lo citaremos en su totalidad:

«En todo sistema moral del que haya tenido noticia, hasta ahora, he podido siempre observar que el autor sigue durante un cierto tiempo el modo de hablar ordinario, estableciendo la existencia de Dios o realizando observaciones sobre los quehaceres humanos, y, de pronto, me encuentro con la sorpresa de que, en vez de las cópulas habituales de las proposiciones: es y no es, no veo ninguna proposición que no esté conectada con un debe o no debe. Este cambio es imperceptible, pero resulta, sin embargo, de la mayor importancia. En efecto, en cuanto que este debe o no debe expresa alguna nueva relación o afirmación, es necesario que ésta sea observada y explicada y que al mismo tiempo se dé razón de algo que parece absolutamente inconcebible, a saber: cómo es posible que esta nueva relación se deduzca de otras totalmente diferentes. Pero como los autores no usan por lo común de esta precaución, me atreveré a recomendarla a los lectores: estoy seguro de que una pequeña reflexión sobre esto subvertiría todos los sistemas corrientes de moralidad...». ${ }^{3}$

Lo que en rigor el fragmento de Hume muestra es que las normas tienen una estructura lógica distinta («nueva relación») a la de los enunciados fácticos. De modo que no parece concebible que éstas puedan deducirse de proposiciones sobre cuestiones de hecho. Si esto ocurre, estaríamos ante un razonamiento falaz, esto es, que puede resultar persuasivo pero que es lógicamente incorrecto. Es a partir de la recuperación de la denuncia humeana por parte de algunos pensadores analíticos en el siglo XX que se percibió la complejidad del pasaje del ser al deber ser; extendiéndose la idea de que existe un abismo lógico insalvable entre el orden factual y el orden normativo.

Recordemos que el mismo Hume no le atribuyó gran importancia a su comentario y que, habiendo aparecido éste en el tercer tomo del Tratado de

1 Dice Popper: «Quizás la más elemental e importante de las cuestiones de la ética sea una cuestión de índole puramente lógica. Me refiero a la imposibilidad de derivar reglas éticas no tautológicas -imperativos, principios de conducta o como quiera que podamos describirlas- a partir de enunciados de hechos. Tan sólo si tenemos bien presente este fundamental detalle lógico podremos empezar a plantearnos los genuinos problemas de la filosofía moral y apreciar toda su dificultad». En «What can logic do for philosophy?», Aristotelian Society Proceedings. Citado por Javier Muguerza, «'Es' y 'Debe'. En torno a la lógica de la falacia naturalista» en Teoría y sociedad. Homenaje al profesor Aranguren, Madrid, 1970, pp. 151-152.

2 P. H. Nowell-Smith, Ethics, London, 1954, p. 37.

3 David Hume, Tratado de la naturaleza humana. Tomo III: De la moral, Orbis, Buenos Aires, 1984, pp. 689-690. 
la naturaleza humana, no lo recogió posteriormente en ningún otro de sus escritos, a diferencia de la mayoría de las ideas vertidas en su primera obra. El argumento es, sin embargo, particularmente relevante no sólo como una objeción para gran parte de los intentos por fundamentar la ética, sino también como el señalamiento de un límite para el razonamiento práctico. Funciona así como una suerte de ley externa a la argumentación moral que invalida ciertas inferencias muy comunes en ese ámbito, aquellas que deducen normas a partir de enunciados que describen algún aspecto de la realidad. ${ }^{4}$

\section{SubJetivismo AXIológico}

Una de las ideas más revolucionarias de Hume en cuestiones morales fue su negación de que la virtud y el vicio sean cualidades inherentes a la acción humana. En un célebre fragmento (que ocupa un importante lugar en la tradición empirista de la ética) sostiene:

«Sea el caso de una acción reconocidamente viciosa: el asesinato intencionado, por ejemplo. Examinadlo desde todos los puntos de vista posibles, a ver si podéis encontrar esa cuestión de hecho o existencia a la que llamáis vicio. Desde cualquier punto de vista que lo miréis, lo único que encontraréis serán ciertas pasiones, motivos, voliciones y pensamientos. No existe ninguna otra cuestión de hecho incluida en esta acción. Mientras os dediquéis a considerar el objeto, el vicio se os escapará completamente. Nunca podréis descubrirlo hasta el momento en que dirijáis la reflexión a vuestro propio pecho y encontréis allí un sentimiento de desaprobación que en vosotros se levanta contra esa acción». ${ }^{5}$

Mediante esta elocuente ilustración, Hume muestra que el vicio -y por oposición la virtud- no son cualidades pertenecientes al objeto valorado, sino al sujeto que valora. No encontraremos nada malo en esta conducta hasta que dirijamos la mirada hacia nosotros mismos; allí nos toparemos con un firme sentimiento de desaprobación frente al crimen. Lo vicioso aparece así como una vivencia del sujeto que contempla, y no como un elemento perteneciente a la acción contemplada.

Nótese también que es el sentimiento -y no la razón, como solía sostenerse- el que hace posible establecer el carácter vicioso o virtuoso de la acción.

4 Asimismo, la lógica deóntica también asume la guillotina de Hume como una ley externa que imposibilita inferencias entre enunciados fácticos y normativos. «(Las leyes de Hume) señalan que ciertas deducciones no pueden hacerse válidamente. Constituyen así un límite, una valla extrasistemática que se impone a la lógica normativa». Delia Echave, María Eugenia Urquijo, Ricardo Guibourg, Lógica, proposición y norma, Astrea, Buenos Aires, 1986.

5 David Hume, Tratado de la naturaleza humana, op. cit., pp. 688-689. 
Hume defendió la idea de que la moralidad está estrechamente vinculada al sentimiento; de modo tal que si las acciones no nos despertaran reacciones emotivas no existiría propiamente la moral.

Estas ideas tuvieron un gran influjo en ética y en metaética. En este último campo, que es el que nos interesa en este trabajo, alentó tanto el desarrollo de tesis subjetivistas como emotivistas. Pero para entender mejor esta diferencia, veamos otro fragmento de la misma obra en la que se habla más explícitamente del juicio moral:

«De esta forma, cuando reputáis una acción o un carácter como vicioso, no queréis decir otra cosa que, dada la constitución de vuestra naturaleza, experimentáis una sensación o sentimiento de censura al contemplarlos». ${ }^{6}$

Este fragmento fue citado a su favor por partidarios de la lectura 'subjetivista individual', según la cual cuando declaramos virtuosa a una acción lo que hacemos es afirmar que poseemos un sentimiento de aprobación por la misma.? Este análisis implica que los juicios morales son descriptivos: describen los propios sentimientos del hablante.

Pero también fue interpretado por otros en clave emotivista, como precursora de esa doctrina. ${ }^{8}$ Para esta corriente, cuando declaramos virtuosa a una acción lo que hacemos es expresar un sentimiento de aprobación por la misma, pero no realizamos una descripción ni de nuestros sentimientos ni de la conducta estimada. Desde esta perspectiva, Hume habría adoptado una posición no cognitivista.

Nótese no obstante la alusión por parte de Hume a la naturaleza humana como fuente de ese sentimiento, lo que limita el carácter estrictamente personal de las experiencias que suscitan juicios morales.

\section{LA RAZÓN, ESCLAVA DE LAS PASIONES}

De acuerdo a Hume, sólo actuamos si experimentamos alguna variante de deseo o de aversión, mientras que aquello que nos resulta indiferente no nos produce reacción. De modo que aún cuando el entendimiento descubra verdades, éstas sólo nos moverán a la acción en conexión con algún deseo o aversión. Nuestras facultades intelectuales por sí solas resultan inactivas, y no

6 David Hume, Tratado de la naturaleza humana, op. cit., p. 689.

7 Esta es la interpretación de Hume ofrecida, entre otros, por Hunter. Cfr. G. Hunter, «Hume on 'is' and 'ought'», Philosophy, n' 38, 1963.

8 La interpretación emotivista o expresivista de la metaética humeana fue defendida en términos generales por Benn y Peters (1959), Flew (1963), Ayer (1980), Price (1988), Snare (1991), y Harman (1996), entre otros. 
puedan por ello ser fuente de distinciones morales. Mediante este razonamiento, Hume pone de manifiesto además una de las características que le atribuye a los juicios morales: el ser capaces de guiar la acción humana, sea por incitación o por censura.

Nuestros sentimientos morales nos movilizan: si aprobamos moralmente un acto que está a nuestro alcance (como ayudar a quien nos lo pide), entonces realizamos ese acto. Si desaprobamos la conducta de robar, omitimos robar. La razón, en cambio, no puede ser fuente de conductas porque no nos dice qué es deseable hacer. Si queremos algo, la razón nos dirá si ese algo es alcanzable, o cómo hacer para alcanzarlo. Pero nunca podrá hacernos querer algo, y menos aún determinar qué debemos querer. Ese es el sentido de la célebre frase de Hume «La razón es, y sólo debe ser, esclava de las pasiones, y no puede pretender otro oficio que el de servirlas y obedecerlas» ${ }^{9}$

El razonamiento seguido por Hume es comúnmente denominado «Argumento Motivacional» y gozó de gran influjo en la metaética. Usualmente se lo relacionó con el emotivismo, pero en términos más generales se lo presenta como una crítica contundente contra el racionalismo ético. Así, posiciones como las de Kant, en la que la razón debe producir un acto sin intervención de inclinación alguna, quedarían excluidas según el argumento humeano. Sin embargo, algunos neo-racionalistas contemporáneos admitieron y retomaron el argumento. Es el caso de Michael Smith, quien consideró que la distinción tajante entre creencias y deseos, con sus respectivas funciones, es la explicación estándar de la psicología humana, y aceptó a la vez la tesis humeana según la cual los juicios morales comprometen a la acción. Lo que se propuso este autor es cómo reconocer estas ideas y evitar a la vez una conclusión no cognitivista (eso es lo que Smith llamó «El problema moral»). ${ }^{10}$

\section{LA VAGUEDAD DEL LENGUAJE MORAL}

Otro aporte metaético de Hume, muy poco citado, puede extraerse a partir de un comentario que realiza en un escrito tardío, titulado «Del criterio del gusto». En ese escrito, el filósofo reconoce que existe una verdadera variedad del gusto en los seres humanos:

«La gran variedad del gusto que prevalece en el mundo es, como la de la opinión, demasiado evidente como no haber sido observada por todo el mundo. [...] aquellos que pueden alargar su vista para contemplar naciones distantes y épocas remotas, se sorprenden aún más por la gran inconsistencia y contradicción.

9 David Hume, Tratado de la naturaleza humana, op. cit., Tomo II, p. 617.

10 Cfr. Michael Smith, The Moral Problem, Blackwell Publishers, Oxford, 1994. 
Siempre tendemos a llamar bárbara a cualquier cosa que diverja de nuestro propio gusto y conocimiento, pero pronto encontramos que ese epíteto insultante nos es devuelto a nosotros mismos» ${ }^{11}$

Se advierte aquí que el adjetivo «bárbaro», que se usa para descalificar a ciertas prácticas, posee un uso relativo, pues desde la cultura así calificada nuestras propias costumbres son vistas con iguales ojos, en sentido contrario. Así, por ejemplo, suele horrorizarnos que las mujeres en ciertos países deban cubrir completamente su cuerpo, al punto de sólo poder mostrar sus ojos; pero visto desde esa cultura, el paso por un kiosko occidental, lleno de tapas con mujeres casi desnudas, produciría una reacción similar.

Continúa Hume:

«...la diferencia entre los hombres es en realidad mayor de lo que a primera vista parece. Es evidente que los escritores de todas las naciones y de todas las épocas concuerdan en el aplauso a la justicia, la humanidad, la magnanimidad, la prudencia, la veracidad y en el rechazo de las cualidades opuestas. [...] Pero cuando los críticos caen sobre particularidades, esta aparente unanimidad de desvanece. Se ve entonces que aquellas voces habían fijado significados diferentes de las mismas expresiones». ${ }^{12}$

Así, por ejemplo, que todos los hombres alaben la justicia no significa que se haya alcanzado un acuerdo moral universal: la concepción de justicia suele ser muy distinta en culturas diversas, y aquello que muchos consideramos injusto (como la esclavitud) puede ser visto por otros como justo. De modo que la diversidad de valores morales es mayor de lo que puede parecernos a primera vista, engañados por los términos morales. La vaguedad de los conceptos morales, esto es, el hecho de que mediante una misma palabra se pueda aludir a características totalmente diferentes, hace posible en ocasiones la generación de un consenso general ilusorio. En este sentido, podríamos decir que las expresiones morales se pueden utilizar en algunos casos para disimular disidencias. Si bien Hume no profundizó en estos análisis, sino que se limitó a constatar los hechos mencionados, creo que su comentario puede dar lugar a nuevas reflexiones metaéticas.

A nuestro juicio, la puntualización de Hume no sólo revela que los términos morales son vagos, sino que por serlo son casi vacíos, y pueden ser llenados

11 David Hume, «Del criterio del gusto», en De la tragedia y otros ensayos sobre el gusto, Biblos, Buenos Aires, 2003, p. 47.

$12 \mathrm{Ibid} .$, p. 48. Cabe agregar que Hume contrasta esta variedad del gusto con la correspondiente a materias que son objeto de opinión y de ciencia, para destacar que éstas últimas difieren más en la apariencia que en la realidad. Reconoce de esta forma una cierta asimetría entre las cuestiones valorativas y las cognoscitivas. 
con contenidos completamente distintos. Pensemos cómo cambió, a lo largo de la historia, el significado de conceptos valorativos tan importantes como «bien de la humanidad», «vida buena», «bien común», felicidad o «fin natural del hombre», y cómo los mismos fueron integrados a ideologías muy diferentes. Así, no es extraño que dos bandos claramente enfrentados en un conflicto enarbolen en su discurso - en alguna medida- la defensa de los mismos valores, interpretando en cada caso que estos les proporcionan la razón a ellos mismos.

\section{LA ARGUMENTACIÓN MORAL}

Pese al reconocimiento de una cierta diversidad moral, Hume defiende la existencia de una valoración correcta, que corresponde a la expresión plena de las pasiones propias de la naturaleza humana bajo ciertas condiciones ideales. Esta cuestión no nos compete en este trabajo, pero sí la formulación humeana de una suerte de prototipo de argumentación para dirimir aquellos casos en que se produce un desacuerdo sobre estas cuestiones, modelo que prácticamente no es tenido en cuenta por los intérpretes de Hume. Recordemos que la argumentación moral es uno de los temas de interés metaético. Si bien propuesta del filósofo escocés está pensada originalmente para discusiones en materia estética, puede ser extrapolada sin mayores inconvenientes para las disputas éticas. Afirma Hume:

«...no sería tan fácil callar al mal crítico que siempre insiste en su propio sentimiento particular y se niega a rendirse a su antagonista. Pero si le mostramos un principio reconocido del arte, si ilustramos este principio con ejemplos cuya operación, por su propio gusto particular, él reconoce como conformes al principio, si probamos que el mismo principio puede ser aplicado al caso presente, en el cual él no percibe ni siente su influencia, se verá obligado a concluir, de todo esto, que el error se encuentra en él...». ${ }^{13}$

Como se advierte, el primer paso de este procedimiento consiste-dado un caso de valoraciones disímiles sobre un mismo punto- en postular un principio general que el otro esté dispuesto a aceptar, a través de ejemplos cuyo sentido moral -para el caso que nos concierne- apruebe.

Supongamos el siguiente ejemplo: se promulga una ley que obliga a pagar un impuesto que para algunos resulta abusivo. Una persona, llamémosle A, afirma que no va a pagarlo, y B intenta convencerlo de que debería hacerlo. Luego de discutir un poco, B invoca como principio la necesidad de respetar la ley aun cuanto ésta nos perjudique o nos parezca injusta, y ofrece varios ejem-

13 Ibid., p. 57.

Contrastes vol. XX No 2 (2015) 
plos que muestran que si las personas no actuaran de acuerdo a tal precepto la sociedad pronto sería un caos, donde cada uno sólo cumpliría aquello que va en su propia conveniencia. De esta forma A acepta el principio y advierte que su caso está contemplado en éste, por lo que le concede la razón a su interlocutor sobre el contrapunto en cuestión.

Aunque en las discusiones reales este modelo de argumentación probablemente tropiece con algunos problemas, en lo esencial resulta correcto y puede ser puesto en práctica. Su principal inconveniente teórico radica en que sólo posibilita llegar a un acuerdo (en el marco de una disputa axiológica sobre algún asunto particular) cuando los interlocutores comparten -real o potencialmente- un principio. No resulta obvio que siempre sea así, especialmente en aquellos casos en que la disputa se produce entre personas con códigos morales muy disímiles.

Recordemos que el propio Hume había advertido que mucho de lo que pasa por acuerdo universal (la exaltación de valores como la justicia o la prudencia) no es tal, admitiendo de esta forma que las diferencias en ética no sólo corresponden a la aplicación de principios sobre ciertos casos, sino que se extiende a veces hasta los valores mismos. Quizás el propio Hume no llevó esta constatación hasta el extremo, y eligió la vía más optimista de considerar a la naturaleza humana como última garante de nuestros sentimientos morales. El filósofo escocés seguramente consideraba que hay valoraciones tan naturales que hasta el más dogmático no podría sino aceptarlas, aún contradiciendo sus prejuicios. Al centrar los sentimientos morales en la naturaleza humana, asumió que algunos principios serían aceptables por todo ser humano.

\section{LENGUAJE EGOÍSTA Y LENGUAJE MORAL}

Otro aporte de Hume al análisis del lenguaje moral, no demasiado citado en obras de metaética pese a su gran actualidad, puede hallarse en Investigación sobre los principios de la moral. Allí Hume defiende algunos aspectos de la especificidad del lenguaje moral en oposición al lenguaje egoísta. Sostiene Hume:

«Cuando un hombre dice que el otro es su enemigo, su rival, su antagonista o adversario, entendemos que habla en el lenguaje del amor a sí mismo, y que expresa sentimientos, peculiares a él mismo y que surgen de su particular circunstancia y situación. Pero cuando concede a un hombre cualquiera los epítetos de vicioso, odioso o depravado, habla entonces otro lenguaje y expresa sentimientos que -espera- han de coincidir con los de su auditorio. Por tanto, él debe aquí alejarse de su privada y particular situación y debe elegir un punto de vista común a él y 
a los demás, debe conmover algún principio de la textura humana y tocar alguna fibra en la cual toda la humanidad debe estar en acuerdo y simpatía». ${ }^{14}$

Así pues, Hume defiende en esta obra que el lenguaje moral, a diferencia del lenguaje que expresa nuestra peculiar circunstancia personal, trasciende las referencias personales y apela a sentimientos que se supone experimenta toda la humanidad. Así, en principio, la consideración de un acto como 'vicioso' pretende reflejar una calificación válida independiente de la persona que lo realiza, y aceptable por su auditorio, cualquiera sea éste.

En ese sentido, parece estar presente en Hume -aunque de forma embrionaria- la idea de que los juicios morales manifiestan expectativas de universalidad, muy lejana al emotivismo que a veces se atribuye a Hume. De hecho, esta idea es defendida principalmente por cierto cognitivismo contemporáneo, especialmente por las escuelas neoracionalistas, aunque también está presente en otras corrientes. ${ }^{15}$ Igualmente, quisiera destacar que, en la particular exposición que de la misma hace Hume, las mencionadas expectativas no son atribuidas a la razón ni parecen ir en desmedro de los elementos emotivos, como la expresión de sentimientos presentes en el juicio y la apelación a los sentimientos del auditorio (pretendidamente principios propios de la naturaleza humana) con la intención de conmoverlos.

En suma, la obra de Hume contiene un conjunto muy valioso de reflexiones sobre el lenguaje moral y la argumentación práctica, sobre las que vale la pena volver. Estas puntualizaciones son tan variadas que dificultan la atribución de un punto de vista metaético claro al propio Hume. Pero ello no impide que, desde las distintas posiciones contemporáneas se pueda seguir dialogando productivamente con el filósofo escocés. En esta cuestión, como en tantas otras, Hume sigue siendo nuestro contemporáneo.

14 David Hume, Investigación sobre los principios de la moral, Espasa Calpe, Madrid, 1991.

15 Así, por caso, el intérprete Francisco Espinoza citó este fragmento, entre otros, para sostener que en Hume el punto de vista moral supone la imparcialidad, y emparentó en ese sentido la posición del filósofo escocés con la del neo-racionalista Jürgen Habermas. Aclaramos que estimamos exagerada la cercanía que presenta este autor entre Habermas y Hume, especialmente debido al explícito anti-racionalismo de este último. Cfr. Francisco Espinoza, «Una lectura habermasiana de la teoría moral de Hume», en Gerardo López Sastre (comp.), David Hume. Nuevas Perspectivas sobre su obra, Ediciones de la Universidad de Castilla - La Mancha, Cuenca, 2005. 


\section{REFERENCIAS BIBLIOGRÁFICAS}

AYER, Alfred, Lenguaje, verdad y lógica, Eudeba, Buenos Aires, 1971.

EsPInOZA, Francisco, «Una lectura habermasiana de la teoría moral de Hume», en López Sastre, Gerardo (comp.), David Hume. Nuevas Perspectivas sobre su obra, Ediciones de la Universidad de Castilla - La Mancha, Cuenca, 2005.

Hudson, W. D., La filosofía moral contemporánea, Alianza Universidad, Madrid, 1987.

Hume, David, Tratado de la naturaleza humana. Tomo III: De la moral, Orbis, Buenos Aires, 1984.

Hume, David, «Del criterio del gusto», en De la tragedia y otros ensayos sobre el gusto, Biblos, Buenos Aires, 2003.

Hume, David, Investigación sobre los principios de la moral, Espasa Calpe, Madrid, 1991.

Joyve, Richard, «Expresivism, Motivation Internalism, and Hume», en Charles Pigden (ed.), Hume on Motivation and Virtue. New Essays, Palgrave-MacMillan, Londres, 2009.

PIdgen, Charles, «If not non-cognitivism, then what?», en Charles Pigden (ed.), Hume on Motivation and Virtue. New Essays, Palgrave-MacMillan, Londres, 2009.

SMith, Michael, The Moral Problem, Blackwell Publishers, Oxford, 1994.

Nicolás ZaVADIVKER es doctor en Filosofía en la Universidad Nacional de Tucumán. Profesor Adjunto a cargo de Ética en la Facultad de Filosofía y Letras de la Universidad Nacional de Tucumán. Investigador asistente de Conicet.

Publicaciones recientes: Libro "Una ética sin fundamentos", UNT, Tucumán, 2004, Libro "La ética y los límites de la argumentación moral”, UNT, Tucumán, 2011.

Linea de investigación: Metaética, Emotivismo, Psicología Moral.

Dirección postal:

Gobernador Celedonio Gutierrez 962 - San Miguel de Tucumán - Argentina. CP: 4000

Dirección electrónica: E-mail: nicozava@yahoo.com 
